\title{
2013s-08 \\ Do Increases in Environmental Risk Reduce Welfare? A Dynamic Game Perspective
}

\author{
Hassan Benchekroun, Ngo Van Long
}

\begin{tabular}{c}
\hline Série Scientifique \\
Scientific Series
\end{tabular}

Montréal

Avril 2013

(C) 2013 Hassan Benchekroun, Ngo Van Long. Tous droits réservés. All rights reserved. Reproduction partielle permise avec citation du document source, incluant la notice (C).

Short sections may be quoted without explicit permission, if full credit, including (C) notice, is given to the source.
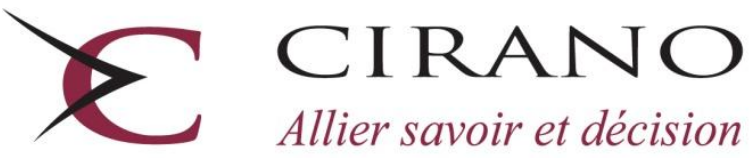

Allier savoir et décision

Centre interuniversitaire de recherche en analyse des organisations 


\section{CIRANO}

Le CIRANO est un organisme sans but lucratif constitué en vertu de la Loi des compagnies du Québec. Le financement de son infrastructure et de ses activités de recherche provient des cotisations de ses organisations-membres, d'une subvention d'infrastructure du Ministère du Développement économique et régional et de la Recherche, de même que des subventions et mandats obtenus par ses équipes de recherche.

CIRANO is a private non-profit organization incorporated under the Québec Companies Act. Its infrastructure and research activities are funded through fees paid by member organizations, an infrastructure grant from the Ministère du Développement économique et régional et de la Recherche, and grants and research mandates obtained by its research teams.

\section{Les partenaires du CIRANO}

\section{Partenaire majeur}

Ministère de l'Enseignement supérieur, de la Recherche, de la Science et de la Technologie

Partenaires corporatifs

Autorité des marchés financiers

Banque de développement du Canada

Banque du Canada

Banque Laurentienne du Canada

Banque Nationale du Canada

Banque Scotia

Bell Canada

BMO Groupe financier

Caisse de dépôt et placement du Québec

École de technologie supérieure (ÉTS)

Fédération des caisses Desjardins du Québec

Financière Sun Life, Québec

Gaz Métro

Hydro-Québec

Industrie Canada

Institut national de la recherche scientifique (INRS)

Investissements PSP

Ministère des Finances et de l'Économie

Power Corporation du Canada

Rio Tinto Alcan

State Street Global Advisors

Transat A.T.

Ville de Montréal

\section{Partenaires universitaires}

École Polytechnique de Montréal

HEC Montréal

McGill University

Université Concordia

Université de Montréal

Université de Sherbrooke

Université du Québec

Université du Québec à Montréal

Université Laval

Le CIRANO collabore avec de nombreux centres et chaires de recherche universitaires dont on peut consulter la liste sur son site web.

Les cahiers de la série scientifique (CS) visent à rendre accessibles des résultats de recherche effectuée au CIRANO afin de susciter échanges et commentaires. Ces cahiers sont écrits dans le style des publications scientifiques. Les idées et les opinions émises sont sous l'unique responsabilité des auteurs et ne représentent pas nécessairement les positions du CIRANO ou de ses partenaires.

This paper presents research carried out at CIRANO and aims at encouraging discussion and comment. The observations and viewpoints expressed are the sole responsibility of the authors. They do not necessarily represent positions of CIRANO or its partners. 


\title{
Do Increases in Environmental Risk Reduce Welfare? A Dynamic Game Perspective
}

\author{
Hassan Benchekroun ${ }^{*}$, Ngo Van Long ${ }^{\star}$
}

\begin{abstract}
Résumé / Abstract
On étudie l'effet d'une augmentation du niveau de risque environnemental. On montre que dans le cas d'un flux de pollution, quand le nombre de joueurs est assez grand, une augmentation de l'incertitude est bonne pour le bien-être social. Par contre, dans le cas d'un stock de pollution, si la situation initiale est sans risque, une augmentation marginale du risque est préjudiciable. Cependant, si l'on commence avec un niveau de risque assez élevé, l'effet d'une augmentation du risque dépend du niveau du stock initial. Si ce dernier est inférieur à un certain seuil, une augmentation du risque peut pallier la défaillance de coopération et améliorer le bien-être social.
\end{abstract}

Mots clés : Tragédie des biens communs, pollution transfrontière, incertitude, risque, jeux différentiels.

We consider the effect of an increase in the risk from pollution. We show that in the case of a flow pollution, when the number of players is sufficiently large, the result of Bramoulle and Treich, showing that a marginal increase of risk in the neighborhood of a risk-free world is welfare-improving, holds even when we consider non-marginal increases in risk and for any initial values of the risk. By contrast, in the case of a stock pollutant, we show that starting in a risk-free world a marginal increase in risk is always welfare reducing. However if the initial value of the risk is sufficiently large, the impact of an increase in risk depends on the level of the stock pollutant. In this non-negligible risk case, it is only for values of the stock of pollution that are below a certain threshold that an increase in risk can mitigate the failure from cooperation over emissions and increase welfare.

Keywords : Tragedy of the commons, transboundary pollution, uncertainty, risk, differential games.

Codes JEL: C73, Q50, D80.

\footnotetext{
${ }^{*}$ Department of Economics, McGill University, Hassan.benchekroun@mcgill.ca

${ }^{\dagger}$ CIRANO and Department of Economics, McGill University, ngo.long@ mcgill.ca
} 


\section{Introduction}

When agents exploit a common property, an increase in risk may increase their welfare. This is a very interesting and important result that has been shown in the case of global pollution, with uncertainty about damages (see Bramoulle and Treich (2009)). The intuition behind this is simple: when polluting agents are risk averse, higher risks tend to lead agent to reduce their emissions. So while the direct effect of higher risk is to reduce their welfare at any given level of emissions, the indirect effect of risk tends to increase their welfare because they emit less, thus reducing the magnitude of the tragedy of the commons ${ }^{1}$. The sum of these effects can therefore be positive or negative. Bramoulle and Treich (2009, Proposition 5) show that if the risk is small, the indirect effect (when there is more than one agent) will outweigh the direct effect, provided that the curvature of the damage function is sufficiently high. Thus Bramoulle and Treich have established a local result (i.e. the initial level of risk is near zero and the increase in risk is marginal), and in a static setting.

The contribution of our paper is two-fold. First, we establish that in a static framework, using a slightly modified model, we can extend the local result of Bramoulle and Treich to a global result: if the number of agents exceeds a critical level, increases in risk always increase welfare, regardless of the initial level of risk and the size of the increase in risk. Second, and more important, we show that in a dynamic setting with stock pollution, a marginal increase in risk will reduce welfare if the initial risk is below a certain threshold but will increase welfare if the initial risk lies above that threshold. ${ }^{2}$ In particular, we show that the threshold value of the initial risk is a decreasing function of the current pollution stock. Thus, in contrast with a flow pollutant, in the case of a stock pollutant a marginal increase in risk in the neighborhood of a 'risk free' environment is always detrimental to welfare.

The intuition behind these contrasting results lies in the feedback nature of Markov

\footnotetext{
${ }^{1}$ Similarly, Sandler and Sterbenz (1990) have examined the case of the fisheries with uncertainty on the harvesting rate. They showed that an increase in uncertainty may induce agents to reduce their harvesting.

${ }^{2}$ Welfare is defined as the present value of the stream of future net benefits, taking into account the stock evolution from the given current level.
} 
perfect strategies in the case of stock pollutant. In the static model with flow pollution, each agent takes the amount of emissions of other agents as given. In this case, a small increase in risk causes each agent to reduce emissions sufficiently to outweigh the small direct welfare loss. In the dynamic game with a stock of pollution, the incentive to reduce emissions is weaker, because each agent knows that if she reduces her own emissions, thereby exerting a negative effect on the future stock of pollution, this will enhance the incentive for other agents to emit more in the future. Therefore, starting from a risk-free world, a small increase in risk does not reduce emissions enough to create a strong indirect effect that would outweigh the unfavorable direct effect of risk on welfare.

The next section covers the case of a flow pollutant. The case of a stock pollutant is analyzed in Section 3. Section 4 concludes.

\section{A flow pollutant}

In this section we assume a static environment, where there is no accumulation of stock. Suppose that there are $N$ agents. Agent $i$ 's emission is denoted by $q_{i} \geq 0$. Let $Q=\sum_{k} q_{k}$ denote the sum of emissions. Assume that the "effective pollution" is $x \equiv(1+\theta) Q \geq 0$ where $\theta$ is a random variable having zero mean, $E(\theta)=0$, and positive variance $\sigma^{2}$, where $\theta \in[-\varepsilon,+\varepsilon]$ with $0<\varepsilon<1$, so that $x$ is non-negative. The damage function is $d(x)$ where $d($.$) is a strictly convex and increasing function. Consider the special case where d(x)=s x^{2}$ with $s>0$.

Then expected damage is

$$
\begin{aligned}
E_{\theta} s x^{2} & =E_{\theta} s(1+\theta)^{2} Q^{2} \\
& =s\left(1+\sigma^{2}\right) Q^{2}
\end{aligned}
$$

We refer to $\sigma^{2}$ as the risk concerning effective pollution, and an increase in risk is captured by an increase in $\sigma^{2}{ }^{3}$

\footnotetext{
${ }^{3}$ We have assumed that $1+\theta>0$ always, and $\theta \in[-\varepsilon, \varepsilon]$ This implies that $\sigma^{2}<1$ always.
} 
The expected net benefit to agent $i$ is assumed to be

$$
W_{i}\left(q_{i}, Q_{-i}, \sigma\right)=A q_{i}-\frac{1}{2} q_{i}^{2}-s\left(1+\sigma^{2}\right) Q^{2}=A q_{i}-\frac{1}{2} q_{i}^{2}-s\left(1+\sigma^{2}\right)\left[q_{i}+Q_{-i}\right]^{2}
$$

with $Q_{-i}=\sum_{k \neq i} q_{k}$. The first order condition for agent $i$ is

$$
\frac{\partial W_{i}}{\partial q_{i}}=A-q_{i}-2 s\left(1+\sigma^{2}\right)\left[q_{i}+Q_{-i}\right]=0
$$

which gives the following best rest response of player $i$

$$
q_{i}=\frac{A}{2 s\left(1+\sigma^{2}\right)+1}-\frac{2 s\left(1+\sigma^{2}\right)}{2 s\left(1+\sigma^{2}\right)+1} Q_{-i}
$$

Assume a symmetric equilibrium, so that $q_{i}=q_{j}=q$ for all $i, j=1, . ., N$. Then

$$
A-q=2 s\left(1+\sigma^{2}\right) N q
$$

or

$$
q=\frac{A}{1+2 s\left(1+\sigma^{2}\right) N}>0
$$

Proposition 1: (a) For $N=1$ or $N=2$, increases in risk will reduce welfare, for all $\sigma^{2} \geq 0$

(b) For any initial $\sigma^{2}$, an increase in risk will increase welfare iff $N$ exceeds the threshold level $n\left(\sigma^{2} ; s\right) \equiv 2+\frac{1}{2 s\left(1+\sigma^{2}\right)}$

$$
N>n\left(\sigma^{2} ; s\right)
$$

(c) For any given $s>0$, if $N>2+\frac{1}{2 s}$, then an increase in risk will increase welfare.

\section{Proof:}

The effect of an increase in $\sigma^{2}$ on Nash equilibrium welfare is

$$
\frac{d W_{i}}{d \sigma^{2}}=\frac{\partial W_{i}}{\partial q_{i}} \frac{\partial q}{\partial \sigma^{2}}+\left[\frac{\partial W_{i}}{\partial Q_{-i}}\right] \frac{\partial Q_{-i}}{\partial \sigma^{2}}+\frac{\partial W_{i}}{\partial \sigma^{2}}
$$

where $q=q\left(\sigma^{2}\right)$, with

$$
\frac{\partial q}{\partial \sigma^{2}}=-\frac{2 s A N}{\left(1+2 s\left(1+\sigma^{2}\right) N\right)^{2}}=-\frac{2 s Q}{1+2 s\left(1+\sigma^{2}\right) N}<0
$$


Therefore

$$
\frac{d W_{i}}{d \sigma^{2}}=0+\left[2 N q s\left(1+\sigma^{2}\right)\right] \frac{2(N-1) s A N}{\left(1+2 s\left(1+\sigma^{2}\right) N\right)^{2}}-s(N q)^{2}
$$

Since $s N q>0$, we have

$$
\operatorname{sign}\left\{\frac{d W_{i}}{d \sigma^{2}}\right\}=\operatorname{sign}\left\{2\left(1+\sigma^{2}\right)(N-1) \frac{2 s A N}{\left(1+2 s\left(1+\sigma^{2}\right) N\right)^{2}}-N q\right\}
$$

which after substitution of $q$ from (3) gives

$$
\operatorname{sign}\left\{\frac{d W_{i}}{d \sigma^{2}}\right\}=\operatorname{sign}\left\{\frac{4 s\left(1+\sigma^{2}\right)(N-1)}{1+2 s\left(1+\sigma^{2}\right) N}-1\right\}
$$

or

$$
\operatorname{sign}\left\{\frac{d W_{i}}{d \sigma^{2}}\right\}=\operatorname{sign}\left\{2 s\left(1+\sigma^{2}\right)(N-2)-1\right\}
$$

Therefore, for $N=1$, or $N=2$, an increase in risk will reduce welfare, for all $\sigma^{2} \geq 0$. This proves part a).

For $N \geq 3$, increases in risk will increase welfare iff

$$
N>n\left(\sigma^{2} ; s\right) \equiv 2+\frac{1}{2 s\left(1+\sigma^{2}\right)}
$$

This proves part b). Note that $n\left(\sigma^{2} ; s\right)$ is strictly decreasing in $\sigma^{2}$ and therefore $n\left(\sigma^{2} ; s\right)<$ $n(0 ; s)=2+\frac{1}{2 s}$. This, along with b) yields c)

Proposition 1 illustrates the point that the findings of Bramoulle and Treich (2009) which were established locally (i.e. in a small neighborhood of a 'risk free environment') can be true, in the case of a flow pollutant, for non marginal changes in risk and in the neighborhood of any $\sigma^{2}>0$. For a flow pollutant, if the number of agents exploiting a common exceeds a critical level, increases in risk always increase welfare, regardless of the initial level of risk.

\section{A stock pollutant}

\subsection{Preliminaries}

We now consider the case the damage from pollution is caused by the accumulation of a stock of pollution. The stock of pollution is denoted $P$. We assume uncertainty in the 
accumulation process

$$
d P=\left(\Sigma_{i=1}^{N} q_{i}-k P\right) d t+\sigma \sqrt{P} d z
$$

where $d z$ is the standard Brownian increment and $\sigma>0$ is considered to be a measure in the volatility of the stock of pollution. This is associated with a volatility of the damage from pollution and therefore we will say that an increase in $\sigma^{2}$ is an increase in risk. Using (4) as the evolution of the stock of pollution allows to obtain the stochastic process followed by $P$ under the optimal control that fits a well known process, namely the Cox-IngersollRoss process. The distribution of $P$ at any future date is then well defined (Athanassoglou $(2010))$.

The net benefit function for player $i=1, \ldots, N$ is assumed to be

$$
B_{i}\left(q_{i}, P\right)=U\left(q_{i}\right)-C(P)
$$

with

$$
U\left(q_{i}\right)=A q_{i}-\frac{1}{2} q_{i}^{2}, \quad A>0
$$

and

$$
C(P)=\frac{s}{2} P^{2}, \quad s>0
$$

Since the evolution of the stock of pollution is stochastic, the damages in any period will also be stochastic. We refer to $\sigma^{2}$ as the risk from pollution and an increase in risk is captured by an increase in $\sigma^{2}$.

Assume that each agent $i$ maximizes its expected present value of net benefits

$$
E \int_{0}^{\infty} e^{-r t}\left[A q_{i}-\frac{1}{2} q_{i}^{2}-\frac{s}{2} P^{2}\right] d t
$$

We are interested in symmetric Markov perfect equilibrium (MPE), i.e. each agent uses a stock-dependent emission strategy $q_{i}=q_{i}\left(P ; \sigma^{2}\right)$, and this strategy maximizes its objective function (6), given all other agents use the same strategy.

It can be shown that if $\sigma^{2}$ is very large, then even at $P=0$, agents will choose zero emissions in the MPE. This would imply zero emissions at all $P>0$. In what follows, we 
focus on the relevant range of $\sigma^{2}$ where emissions are non-negative and assume that $\sigma^{2}<\widehat{\sigma}^{2}$ where $\widehat{\sigma}^{2}$ is the threshold value such that at $P=0$, all agents will choose to have zero emissions. More precisely the value of $\widehat{\sigma}^{2}$ is the smallest $\sigma^{2}$ such that $q_{i}\left(P ; \sigma^{2}\right)=0$ for all $P \geq 0$. It can be shown that ${ }^{4}$

$$
\widehat{\sigma}^{2}=\frac{4 A(k+r)(2 N-1)}{\sqrt{(2 k+r)^{2}+4 s(2 N-1)}-(2 k+r)}+2 A(N-1)
$$

Assumption A1: $\sigma^{2}<\widehat{\sigma}^{2}$

We will maintain Assumption A1 in all that follows. The following lemmas are useful for establising our main result for section 3, Proposition 2.

Lemma 1: Consider the linear strategy

$$
q\left(P ; \sigma^{2}\right)=X+Y P>0 \text { for all } P \in[0, \bar{P}), \text { and } q(P)=0 \text { for all } P \geq \bar{P}
$$

where $X$ and $Y$ are given by

$$
\begin{gathered}
Y=\frac{1}{2(2 N-1)}\left((2 k+r)-\sqrt{4 s(2 N-1)+(2 k+r)^{2}}\right)<0 \\
X=\frac{Y \sigma^{2}+2 A(k+r-(N-1) Y)}{2(k+r-(2 N-1) Y)}>0 \text { for } \sigma^{2}<\widehat{\sigma}^{2}
\end{gathered}
$$

and where

$$
\bar{P} \equiv-\frac{X}{Y}>0
$$

The n-tuple vector of strategies $(q, . ., q)$ where each agent chooses the above emission strategy $q\left(P ; \sigma^{2}\right)$ is a Markov Perfect Nash Equilibrium.

Lemma 2: Under the Nash equilibrium strategy profile reported in Lemma 1, the expected pollution stock at time $t$ is

$$
E[P(t)]=P_{0} e^{-(k-N Y) t}+\frac{N X}{k-N Y}\left(1-e^{-(k-N Y) t}\right)
$$

It follows that $E[P(t)]$ converges to its steady state value $P_{\infty}$ where

$$
\bar{P}>P_{\infty}=\frac{X}{k N^{-1}-Y}>0
$$

\footnotetext{
${ }^{4}$ At this value of $\sigma^{2}$ we can see that $X$ defined in Lemma 1 below vanishes.
} 
Lemma 3: Starting from any $P_{0} \in[0, \bar{P})$, the expected welfare of agent $i$, given by the maximized value of (6), is a concave and decreasing function of $P_{0}$ and is given by

$$
W_{i}\left(P_{0} ; \sigma^{2}\right)=\frac{Y}{2}\left(P_{0}\right)^{2}-(A-X) P_{0}+c \text { for all } P_{0} \in[0, \bar{P}]
$$

where $A-X>0$ and

$$
c=\frac{1}{2 r}\left(A^{2}+(2 N-1) b^{2}-2 A N b\right)
$$

where

$$
b=-\frac{Y\left(\frac{1}{2} \sigma^{2}+A N\right)}{k+r-(2 N-1) Y}=A-X>0
$$

The details of the proof of Lemma 1-3 are omitted, as they can be readily derived from arguments found in Dockner et al. (2000).

\subsection{The impact of an increase in risk}

An increase in risk reduces emissions. This is straightforward from Lemma 1:

$$
\frac{\partial q\left(P ; \sigma^{2}\right)}{\partial \sigma^{2}}=\frac{\partial X}{\partial \sigma^{2}}=\frac{Y}{2(k+r-(2 N-1) Y)} \equiv B<0
$$

As a consequence we have that the steady state value of the expected stock of pollution $P_{\infty}$ is decreasing in $\sigma^{2}$. It tends to zero as $\sigma^{2} \rightarrow \widehat{\sigma}^{2}$.

As the risk increases, agents mitigate the effect of the risk by reducing their emissions. This is in line with the precautionary principle and the findings of Bramoulle and Treich (2009) in the case of a marginal increase in risk and flow pollution.

We now address the main issue which is to determine if the positive impact on welfare resulting from the decrease in all countries emissions can outweigh the negative effect of an increase in risk.

\section{Lemma 4:}

\footnotetext{
${ }^{5}$ Note that if $P>\bar{P}$, then $q=0$, and hence the value function will not be quadratic for $P \in(\bar{P}, \infty)$; see e.g. Kamien and Fershman (1987), or Benchekroun (2008). To avoid this complication, we restrict attention to the value function for $P_{0} \in[0, \bar{P}]$.
} 
i) The function $W_{i}\left(P_{0} ; \sigma^{2}\right)$ in $(9)$ is strictly convex in $\sigma^{2}$ for all $\sigma^{2} \in\left[0, \widehat{\sigma}^{2}\right)$.

ii) The shadow cost of unit of stock of pollution $-\frac{\partial W_{i}}{\partial P}$ is strictly increasing in $\sigma^{2}$ for all $\sigma^{2} \in\left[0, \widehat{\sigma}^{2}\right)$

\section{Proof:}

Note that from (8) and (7), $X$ is a linear function of $\sigma^{2}$ and that $Y$ is independent of $\sigma^{2}$. Therefore $\frac{\partial^{2} W_{i}}{\left(\partial \sigma^{2}\right)^{2}}=\frac{\partial^{2} c}{\left(\partial \sigma^{2}\right)^{2}}$. From (10) rewrite $c$ as

$$
c=\frac{1}{2 r}\left((2 N-1) X^{2}-2 A(N-1) X\right)
$$

Then from

$$
W_{i}\left(P_{0} ; \sigma^{2}\right)=\frac{Y}{2}\left(P_{0}\right)^{2}-(A-X) P_{0}+c \text { for all } P_{0} \in[0, \bar{P}]
$$

we have that

$$
\frac{\partial W_{i}}{\partial \sigma^{2}}=B P_{0}+\left[\frac{B}{r}(X(2 N-1)-(N-1) A)\right]
$$

and

$$
\frac{\partial^{2} W_{i}}{\left(\partial \sigma^{2}\right)^{2}}=\frac{1}{r} B^{2}(2 N-1)>0
$$

This completes part (i).

For part (ii) we have

$$
\frac{\partial W_{i}}{\partial P}=X-A<0
$$

and therefore

$$
\frac{\partial\left(\frac{\partial W_{i}}{\partial P}\right)}{\partial \sigma^{2}}=B=\frac{\partial X}{\partial \sigma^{2}}<0 .
$$

In proving (i) we computed $\frac{\partial W_{i}}{\partial \sigma^{2}}$ given in (12), the right hand side consists of two terms. The first term, $B P_{0}$, is non positive. If $N \geq 2$, it can be shown that the term inside the square brackets is positive iff $\sigma \in(\bar{\sigma}, \widehat{\sigma})$, where

$$
\bar{\sigma}=\sqrt{2 \frac{A(k+r)}{a}\left(\frac{N}{2 N-1}\right)}
$$

The term inside the square brackets on the right hand side of eq. (12) is increasing in $\sigma^{2}$, for all $\sigma^{2} \in\left[0, \widehat{\sigma}^{2}\right)$. 
We can therefore infer that:

- If $N=1$, then the term inside the square brackets is negative for all $\sigma^{2} \in\left[0, \widehat{\sigma}^{2}\right)$, and in this case increases in risk reduce welfare.

- For $N \geq 2$, if $P_{0}=0$ then $\frac{\partial W_{i}\left(0, \sigma^{2}\right)}{\partial \sigma^{2}}<0$ iff $\sigma<\bar{\sigma}$,so $W_{i}\left(0, \sigma^{2}\right)$ is decreasing in $\sigma^{2}$ in the range $\left(0,(\bar{\sigma})^{2}\right)$ and is increasing in $\sigma^{2}$ in the range $\left((\bar{\sigma})^{2},(\widehat{\sigma})^{2}\right)$, i.e. $W_{i}\left(0, \sigma^{2}\right)$ attains its minimum at $\sigma^{2}=(\bar{\sigma})^{2}$.

- For $N \geq 2$, if $P_{0}>0$ then $\frac{\partial W_{i}\left(P_{0}, \sigma^{2}\right)}{\partial \sigma^{2}}=B P_{0}<0$ at $\sigma^{2}=(\bar{\sigma})^{2}$, and there exists a critical value $\sigma_{c}$ (which depends on $P_{0}$ ) such that $\frac{\partial W_{i}\left(P_{0}, \sigma^{2}\right)}{\partial \sigma^{2}}>0$ for all $\sigma>\sigma_{c}$ (and $\frac{\partial W_{i}\left(P_{0}, \sigma^{2}\right)}{\partial \sigma^{2}}<0$ for all $\left.\sigma<\sigma_{c}\right)$. Note that $\sigma_{c}>\bar{\sigma}$.

Note that ii) of Lemma 4 also gives $\frac{\partial\left(\frac{\partial W_{i}}{\partial \sigma^{2}}\right)}{\partial P}<0$. Therefore the smaller the stock of pollution the more likely an increase in $\sigma^{2}$ will result in an increase in welfare. We also have that there exists $\widetilde{P}$ (which depends on $\sigma$ ) such that $\frac{\partial W_{i}}{\partial \sigma^{2}}>0$ for all $P<\widetilde{P}$ and it is straightforward to show that

$$
\widetilde{P}=-\frac{1}{r}(X(2 N-1)-A(N-1))>0 \text { for } \sigma>\bar{\sigma} .
$$

A sufficient condition for the existence of a range of $\sigma^{2}$ over which $\frac{\partial W_{i}}{\partial \sigma^{2}}>0$ is that $\widetilde{P}>0$.

These results are summed up in the following proposition.

\section{Proposition 2:}

Let $\bar{\sigma} \equiv \sqrt{2 \frac{A(k+r)}{a}\left(\frac{N}{2 N-1}\right)}$,

(i) If $\sigma<\bar{\sigma}$, then for all $P_{0} \geq 0$, any small increase in $\sigma$ (such that $\sigma$ remains lower than $\bar{\sigma}$ ) will reduce welfare.

(ii) If $\sigma>\bar{\sigma}$, then there exists a positive threshold value $\widetilde{P}$ (which depends on $\sigma$ ) such that for all $P_{0} \in[0, \widetilde{P})$, any increase in $\sigma$ will increase wellfare. (As long as $\sigma^{2}<\widehat{\sigma}^{2}$ ).

We note that Proposition 2 in some sense extends the finding of Bramoulle and Treich, as well as Proposition 1 above, that an increase in risk can be welfare increasing, to the case where emissions accumulate into a damaging stock pollutant. However, Proposition 2 also establishes that when we are initially in a risk-free world $(\sigma=0)$, a marginal increase in 
risk is always welfare reducing. This contrasts with Bramoulle and Treich and Proposition 1 above, which establishes conditions under which, starting in a risk free world with $N \geq 2$, a marginal increase in risk is welfare-improving. ${ }^{6}$

The intuition behind the contrast between the case of a flow pollutant and that of a stock pollutant can be explained by the difference in behavior implied by the strategies considered. In the case of a flow pollutant, when agent $i$ solves her problem, she takes the emissions (the strategy of a player corresponds to a level of emissions) of the other players as given (player $i$ 's reaction function (2)). This is in contrast with the case of a stock pollutant. In that case player $i$ takes the strategy of the other players as given, however a strategy is a Markovian rule of emissions that depends on the stock of pollutant. When player $i$ determines her best response 'functional', if the Nash conjecture implies strategies that are downward sloping functions of the stock of pollution (as is the case in the equilibrium at hand), then the incentive of player $i$ to decrease its emissions following an increase in risk is diminished sinced a decrease in her emissions will be accompanied by a decrease in the pollution stock which in turn results in larger emissions of the other players. Since each player has a reduced incentive to decrease its emissions the outcome is that, when the initial level of risk is small enough, the overall reduction of emissions due to increased risk is not enough to compensate the direct negative welfare effect of increased risk.

\footnotetext{
${ }^{6}$ They note that a sufficient condition is that $d(e)=d_{0} e^{\alpha}$ where $\alpha>1$. They say that increase in a small risk will increase welfare iff

$$
\left(\frac{d}{d^{\prime}}\right)^{\prime}>-(N-2) / N
$$

If $d=d_{0} e^{\alpha}$, then

$$
\frac{d}{d^{\prime}}=\frac{e^{\alpha}}{\alpha e^{\alpha-1}}=\frac{e}{\alpha}
$$

$\left(\frac{d}{d^{\prime}}\right)^{\prime}=\frac{1}{\alpha}>-\frac{N-2}{N}$ if $N \geq 2$.

$$
-\frac{N-2}{N}=1
$$

and $\left(\frac{d}{d^{\prime}}\right)^{\prime}=\frac{1}{\alpha}<1$, so with $N=1$, an increase in uncertainty will reduce welfare.
} 


\section{Conclusion}

We considered the effect of an increase in the risk from pollution. We have shown that in the case of a flow pollution, when the number of players is sufficiently large, the result of Bramoulle and Treich, showing that a marginal increase of risk in the neighborhood of a riskfree world is welfare-improving, holds even when we consider non-marginal increases in risk and for any initial values of the risk. By contrast, in the case of a stock pollutant, we have shown that starting in a risk-free world a marginal increase in risk is always welfare reducing. However if the initial value of the risk is sufficiently large, the impact of an increase in risk depends on the level of the stock pollutant. It is only for values of the stock of pollution that are below a certain threshold that an increase in risk can mitigate the failure from cooperation over emissions and increase welfare.

While we have followed the mainstream literature and focused on the case of a known and fixed damage function, it would be interesting to enrich the model by including a phase where each agent can invest in damage control. Athanassoglou and Xepapadeas (2012) have recently shown, in the case of a social planner, that this addition can bring interesting insights, in particular regarding the applicability of the precautionary principle to environmental policies. They considered a dynamic model of pollution control with uncertain stock dynamics ${ }^{7}$. They showed that the optimal investment in damage control is increasing in the degree of uncertainty, thus confirming the precautionary principle's general wisdom. However mitigation efforts may not be increasing with uncertainty. Including the possibility of investment in damage control into our multi-agents framework could therefore have ambiguous effects on agents' reaction to an increase in risk and can thus be a promissing direction for future research.

\footnotetext{
${ }^{7}$ Athanassoglou and Xepapadeas (2012) examined the more challenging case of Knightian uncertainty where the social planner takes into account the possibility of model misspecifications when choosing her optimal policies.
} 


\section{References}

[1] Athanassoglou, S., (2010), "Dynamic Nonpoint source pollution control policy: ambient transfer and uncertainty," Journal of economic dynamics and control, vol 34(12), 24942509.

[2] Athanassoglou, S. and A. Xepapadeas, (2012), "Pollution control with uncertain stock dynamics: When, and how, to be precautious," Journal of environmental economics and management, vol 63(3), 304-320.

[3] Benchekroun, H., (2003), 'Unilateral production restrictions in a dynamic duopoly,' Journal of Economic Theory 111, 214-239.

[4] Benchekroun, H., (2008), 'Comparative dynamics in a productive asset oligopoly,' Journal of Economic Theory 138, 237-261.

[5] Bramoulle, Y. and N. Treich, (2009),"Can Uncertainty Alleviate the Commons Problem?," Journal of the European Economic Association, MIT Press, vol. 7(5), pages 10421067, 09.

[6] Ferhstman, C. and M. Kamien (1987), "Dynamic duopolistic competition with sticky prices," Econometrica 55, 1151-64.

[7] Dockner E., S. Jorgensen, N.V. Long and G. Sorger (2000), Differential Games In Economics and Management Science. Cambridge University Press.

[8] Sandler, T. and F.P. Sternbenz, (1990), "Harvest uncertainty and the tragedy of the commons", Journal of Environmental Economics and Management, 18, Issue 2, Part 1, Pages 155-167. 